\title{
Cloreto de potássio revestido em efeito residual no feijoeiro de inverno irrigado na região de cerrado
}

\section{Coated potassium choride in residual effect on winter common bean irrigated in Cerrado region}

\author{
Mateus Augusto de Carvalho Rodrigues ${ }^{1}$; Salatiér Buzetti ${ }^{2 a}$; \\ Paulo Ricardo Maestrelo ${ }^{1}$; Ana Carolina Marostica Lino; ${ }^{1}$ Marcelo Carvalho \\ Minhoto Teixeira Filho ${ }^{2 b^{*}}$; Marcelo Andreotti ${ }^{2 c}$; Cássia Maria de Paula Garcia ${ }^{3}$
}

\section{Resumo}

Com a finalidade de manter os nutrientes disponíveis para as plantas têm-se buscado fertilizantes de liberação controlada. Neste contexto, objetivou-se avaliar o efeito residual de doses de potássio usando cloreto de potássio e cloreto de potássio revestido por polímeros, aplicados na cultura do milho, nos componentes de produção e a produtividade do feijoeiro de inverno irrigado, cultivado em sucessão, em condições de cerrado. O experimento foi conduzido em Selvíria - MS, com coordenadas geográficas de $51^{\circ} 22^{\prime}$ de longitude Oeste e $20^{\circ} 22^{\prime}$ de latitude Sul, num Latossolo Vermelho distrófico de textura argilosa, em 2009 e 2010. O delineamento estatístico utilizado foi o de blocos casualizados, com quatro repetições, dispostos em um esquema fatorial 4 x 2, sendo: 4 doses de $\mathrm{K}_{2} \mathrm{O}(0,40,80$ e $120 \mathrm{~kg}$ ha$\left.{ }^{1}\right)$ e 2 fontes de potásio ( $\mathrm{KCl}$ e $\mathrm{KCl}$ revestido por polímeros) aplicadas na semeadura do milho. $\mathrm{O}$ $\mathrm{KCl}$ revestido por polímeros teve o mesmo efeito residual que $\mathrm{KCl}$ convencional, pois proporcionou resultados semelhantes para os teores foliares de K e de clorofila, nos componentes de produção e na produtividade de grãos de feijão de inverno irrigado. O incremento das doses de potássio na cultura anterior (milho) porporcionou efeito residual, pois influenciou positivamente o número de grãos por planta em 2009 e aumentou linearmente o teor de clorofila e a produtividade de grãos de feijão de inverno irrigado em 2010, independentemente da fonte de K.

Palavras-chave: Phaseolus vulgaris, adubação potássica, feijão, fertilizante revestido, doses de potássio, sistema plantio direto

\begin{abstract}
In order to maintain the nutrients available to plants have been studied controlled release fertilizers. In this context, the objective was to evaluate the residual effect of doses of potassium chloride, coated or not, applied in the corn crop, regarding the crop components and grains yield of irrigated winter common bean, cultivated in followed, in Cerrado region. The experiment was conducted in Selvíria MS, Brazil, $51^{\circ} 22^{\prime}$ west longitude and $20^{\circ} 22^{\prime}$ south latitude, in a clayey Oxisol, in 2009 and 2010 . A randomized block design with four repetitions was used, disposed in a factorial scheme 4 x 2, being: four $\mathrm{K}_{2} \mathrm{O}$ doses $\left(0,40,80\right.$ and $\left.120 \mathrm{~kg} \mathrm{ha}^{-1}\right)$ and two potassium sources (potassium chloride and coated potassium chloride by polymers) applied at sowing in the corn crop. The coated potassium chloride by
\end{abstract}

\footnotetext{
${ }^{1}$ Discente(s) em Agronomia da Faculdade de Engenharia da Universidade Estadual Paulista “Júlio de Mesquita Filho" UNESP, Campus De Ilha Solteira. E-mail: mateusdinho@hotmail.com; paulomaestrelo@hotmail.com; carol_marostica@hotmail.com

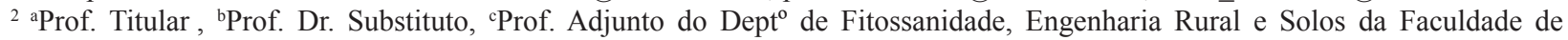
Engenharia da UNESP, Campus de Ilha Solteira. ${ }^{2 a}{ }^{2 c}$ Bolsistas em produtividade pelo CNPq. E-mail: sbuzetti@agr.feis.unesp.br; mcmtf@yahoo.com.br; dreotti@agr.feis.unesp.br

${ }^{3}$ Mestranda em Agronomia da Faculdade de Engenharia da UNESP, Campus de Ilha Solteira. E-mail: cassiampg@yahoo.com.br

* Autor para correspondência
} 
polymers have the same residual effect as conventional $\mathrm{KCl}$, because it provides results similar for the $\mathrm{K}$ and chlorophyll leaf contents, crop components and grains yield of winter common bean irrigated. The increment of potassium doses in the previous crop (corn) have residual effect, because it influenced positively the number of grains per plant in 2009 and increased linearly the chlorophyll leaf content and the grains yield of winter common bean irrigated in 2010, regardless of the source used for K.

Key words: Phaseolus vulgaris, potassium fertilization, common bean, coated fertilizer, potassium doses, no-tillage system

\section{Introdução}

O feijoeiro comum (Phaseolus vulgaris L.) é uma cultura de grande importância sendo a espécie mais cultivada entre as demais do gênero Phaseolus. No Brasil na safra 2010/11 estima-se uma área cultivada de 3,91 milhões de hectares, com uma produtividade média de $964 \mathrm{~kg} \mathrm{ha}^{-1}$, e produção de 3,77 milhões de toneladas de grãos (COMPANHIA NACIONAL DE ABASTECIMENTO, 2011).

O feijão tem importante papel na alimentação da população brasileira em função do seu alto valor protéico (22-26\%), podendo substituir a proteína animal, que apresenta alto custo e por isso dificuldades de compra pela população de baixa renda (BARAMPAMA; SIMARD, 1993). Além disso, pode-se encontrar no feijão, carboidratos, vitaminas, minerais, fibras e compostos fenólicos com ação antioxidante.

A disponibilidade de nutrientes influencia a formação do embrião e dos cotilédones, com resultados eficazes sobre o vigor e a qualidade fisiológica da semente (TEIXEIRA et al., 2005), podendo afetar o potencial de armazenamento do lote e persistir no campo, influenciando o estabelecimento da cultura, o desenvolvimento da planta, a uniformidade da lavoura e a sua produtividade (CARVALHO; NAKAGAWA, 2000). O potencial produtivo e as respostas na produção de grãos têm sido mais eficazes pela aplicação de fósforo $(60 \%$ de influência absoluta na produção de matéria verde), cálcio (50\%), zinco (30\%), nitrogênio (20\%) e potássio (10\%) (OLIVEIRA; ARAÚJO; DUTRA, 1996).

O feijoeiro é uma planta exigente em nutrientes, em função, principalmente do seu sistema radicular pouco desenvolvido e pouco profundo, além de apresentar ciclo curto de 90 a 100 dias, portanto, é fundamental que o nutriente seja colocado à disposição da planta em tempo e local adequados. O padrão de absorção do potássio apresenta dois períodos de grande demanda: entre 25 e 35 dias e entre 45 e 55 dias da emergência (ROSOLEM; MARUBAYASHI, 1994). O primeiro período corresponde à diferenciação dos botões florais, quando a cultura absorve em média, $1,7 \mathrm{~kg}$ de $\mathrm{K} \mathrm{ha}^{-1}$ $\mathrm{dia}^{-1}$, o segundo, ao final do florescimento e início de formação das vagens, quando o feijoeiro absorve em média, de 2,2 a 3,3 $\mathrm{kg}$ de $\mathrm{K} \mathrm{ha}^{-1} \mathrm{dia}^{-1}$. A partir do final do florescimento a absorção de K é muito baixa (ROSOLEM; MARUBAYASHI, 1994).

$\mathrm{Na}$ década de 90, as recomendações oficiais de adubação para a cultura do feijão evoluíram consideravelmente no Brasil, principalmente em cultivo de inverno. As principais inovações estão na recomendação de doses de acordo com a produtividade esperada, influência do tipo de solo, manejo, época de semeadura e material genético (CANTARELLA; DUARTE, 2004). Dentre os fertilizantes minerais potássicos disponíveis no mercado, o cloreto de potássio $(\mathrm{KCl})$ predomina na agricultura brasileira, resultado da maior disponibilidade e da melhor relação custo-benefício (ECHER; FOLONI; CRESTE, 2009).

No entanto, vários inconvenientes econômicos e ambientais associados à utilização de fertilizantes convencionais tornam-se foco de preocupação em todo o mundo (JAMES; SOJKA, 2008; NI; LIU; LÜ, 2009). Os fertilizantes são os que representam maior valor no custo de produção e os que mais limitam a produtividade de algumas culturas (YAN, 
2008). Dentre os fertilizantes potássicos, o cloreto de potássio $(\mathrm{KCl})$ é o mais utilizado no Brasil. Porém, a literatura aponta perdas por lixiviação de $\mathrm{K}$ na ordem de 50-70\% (AUOADA et al., 2008; WU; LIU, 2008), quando aplicados de forma inadequada aos solos (SOUSA; REIN, 2009), são perdidos para o ambiente sem serem absorvidos pelas plantas, o que provoca não só grandes perdas de recursos econômicos, mas também prejuízos ambientais devido à poluição dos recursos hídricos (GE et al., 2002; SHAVIT; REISS; SHAVIV, 2002).

Um método para superar essas deficiências envolve o uso de fertilizantes de liberação lenta (XIE et al., 2011). Os fertilizantes com inibidores ou de estabilização são produtos que reduzem as perdas de nutrientes por retardarem a conversão das formas originais do fertilizante em formas que podem ser facilmente perdidas (BLAYLOCK, 2007). Por isso, os fertilizantes de liberação lenta podem reduzir o número de adubações feitas durante um ciclo da cultura, reduzindo assim os custos de produção e a lixivação de íons para o lençol freático. $\mathrm{O}$ produto libera os nutrientes gradativamente, podendo assim, atender melhor a necessidade de cada cultura, diminuindo possíveis danos causados às raízes pela alta concentração de sais e com distribuição mais homogênea dos nutrientes no substrato, favorecendo o fornecimento e a demanda fisiológica da planta (ROSSA, 2008).

Guareschi et al. (2011) constataram que a aplicação a lanço de $\mathrm{KCl}$ revestido por polímeros, 15 dias antes da semeadura, proporcionou maior produção de matéria seca, número de vagens por planta e produtividade de grãos de soja em relação ao $\mathrm{KCl}$ convencional. Porém, estes autores verificaram que quando aplicados na semeadura, estes fertilizantes conferiram a mesma produtividade de grãos e de matéria seca de soja, em Rio Verde - GO. Já Valderrama et al. (2011) verificaram que os fertilizantes revestidos por polímeros (uréia, superfosfato triplo e cloreto de potássio), isoladamente, tiveram a mesma eficiência que os mesmos fertilizantes convencionais para produtividade de grãos de milho, em Selvíria - MS.

Contudo no Brasil, ainda há poucas pesquisas com fertilizantes revestidos por polímeros quando comparados com outros países de clima temperado, o que torna necessária a condução de experimentos em condições edafoclimáticas brasileiras, principalmente em regiões como a do cerrado que apresenta grande potencial para produção de grãos, como feijão. Estes trabalhos são de extrema importância, pois permitem estabelecer relações custo-benefício, bem como quantificar a eficiência agronômica da adubação, validando, dessa forma, o emprego desse tipo de fertilizante (GIRARDI; MOURÃO FILHO, 2003).

$\mathrm{Na}$ literatura constam respostas ao efeito residual da adubação potássica quando as culturas anteriores são o girassol, soja e trigo (BORKERT et al., 1997), ou o milho (VIÉGAS; FREIRE, 1958). Portanto, a utilização do $\mathrm{KCl}$ revestido por polímeros em sistemas de produções com culturas anuais pode ser interessante para aumentar o efeito residual do potássio no solo, podendo assim, suprir as necessidades deste nutriente da cultura em sucessão, como a do feijão que é considerado exigente em potássio. Sendo assim, o objetivo deste trabalho foi avaliar o efeito residual de doses de potássio usando cloreto de potássio e cloreto de potássio revestido por polímeros aplicados na cultura do milho, no teor de clorofila e de potássio foliar, além dos componentes de produção e a produtividade do feijoeiro de inverno irrigado, cultivado em sucessão, em condições de cerrado.

\section{Material e Métodos}

O experimento foi conduzido em 2009 e 2010, em área experimental pertencente à Faculdade de Engenharia - UNESP, localizada no município de Selvíria - MS, com coordenadas geográficas de $51^{\circ} 22^{\prime}$ de longitude Oeste e $20^{\circ} 22^{\prime}$ de latitude Sul e altitude de $335 \mathrm{~m}$. O solo é classificado como Latossolo Vermelho distrófico, textura argilosa (SANTOS et al., 2006), com valores de 
granulometria de 420,50 e $530 \mathrm{~g} \mathrm{~kg}^{-1}$ de areia, silte e argila, respectivamente. Esse solo foi originalmente ocupado por vegetação de cerrado e cultivado por culturas anuais há mais de 26 anos. As características químicas do solo determinadas antes da instalação do experimento com milho safra 2008/2009, segundo metodologia proposta por Raij et al. (2001) apresentaram os seguintes resultados: $32 \mathrm{mg} \mathrm{dm}^{-3}$ de P (resina); $29 \mathrm{~g} \mathrm{dm}^{-3}$ de M.O.; 5,4 de $\mathrm{pH}\left(\mathrm{CaCl}_{2}\right) ; \mathrm{K}, \mathrm{Ca}, \mathrm{Mg}, \mathrm{H}+\mathrm{Al}=2,2 ; 31,0 ; 16,0$ e $29,0 \mathrm{mmol}_{\mathrm{c}} \mathrm{dm}^{-3}$, respectivamente e $63 \%$ de saturação por bases.
O clima da região é Aw, de acordo com Köppen, definido como tropical úmido, com estação chuvosa no verão e seca no inverno. As médias anuais de temperatura e precipitação pluvial são de $23,5^{\circ} \mathrm{C}$ e $1.370 \mathrm{~mm}$, e a umidade relativa do ar fica entre 70 e $80 \%$. Os valores diários de temperatura média e umidade relativa do ar, bem como os totais diários de precipitação pluvial, registrados durante o período de condução do experimento, estão apresentados na Figura 1.

Figura 1. Precipitação pluvial $(\mathrm{mm})$, temperatura média $\left({ }^{\circ} \mathrm{C}\right)$ e umidade relativa do ar $(\%)$ durante a condução do experimento com a cultura do feijão de inverno irrigado. Selvíria - MS, 2009 (A) e 2010 (B).
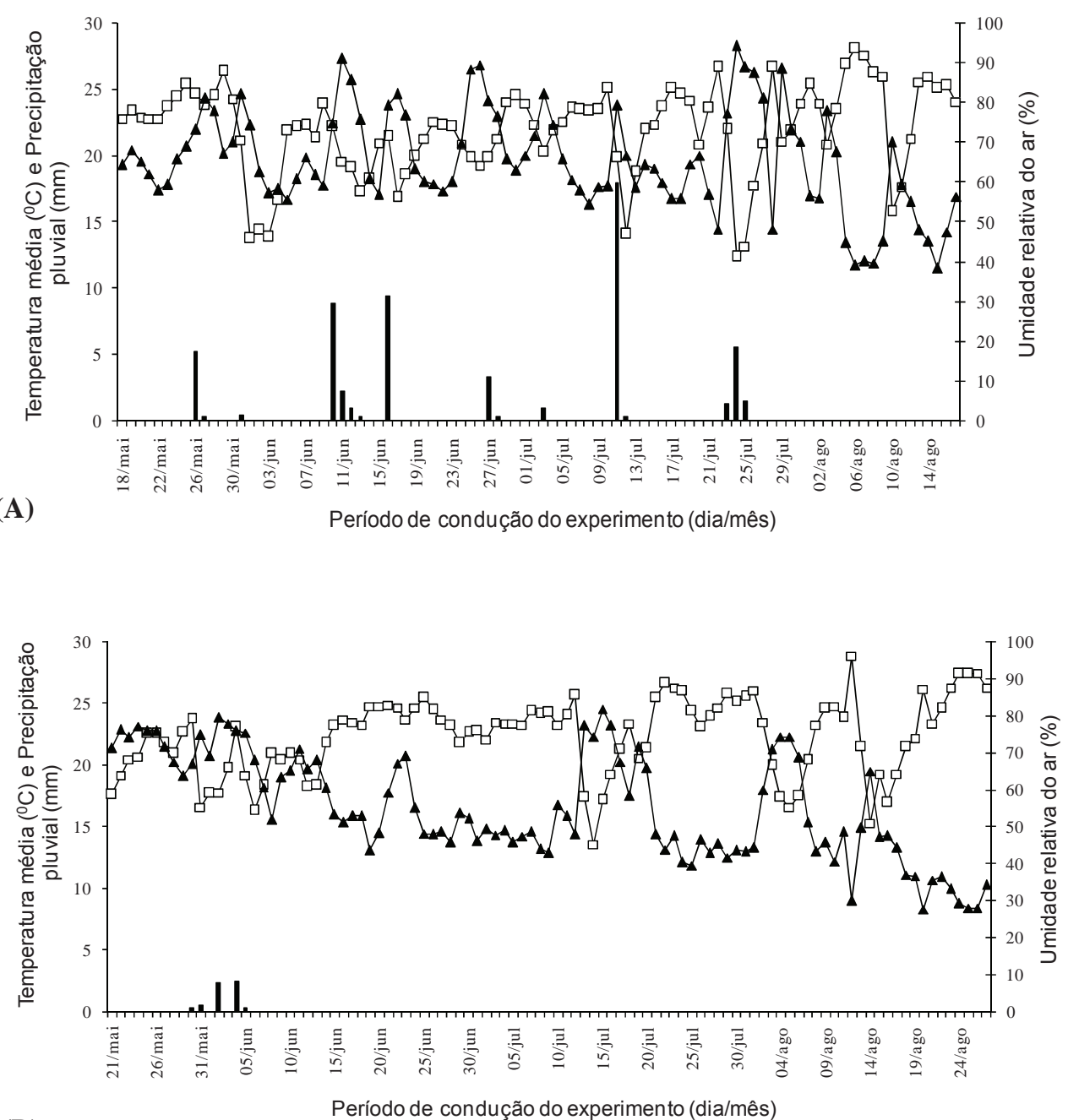

(B)

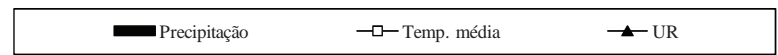

Fonte: Elaboração dos autores. 
O delineamento estatístico foi o de blocos casualizados, em um esquema fatorial 4 × 2 , ou seja, quatro doses de $\mathrm{K}_{2} \mathrm{O}(0,40,80$ e $120 \mathrm{~kg}$ ha $\left.{ }^{1}\right)$ aplicadas na linha de semeadura da cultura do milho, antecessora à cultura do feijão, duas fontes de potássio (cloreto de potássio e cloreto de potássio revestido por polímeros), com 4 repetições. As doses de potássio foram estabelecidas com base na dose recomendada total $\left(70 \mathrm{~kg} \mathrm{ha}^{-1}\right.$ de $\left.\mathrm{K}_{2} \mathrm{O}\right)$, obtida conforme o teor de $\mathrm{K}\left(2,2 \mathrm{mmol}_{\mathrm{c}} \mathrm{dm}^{-3}\right)$ no solo e a produtividade esperada $\left(8-10 \mathrm{tha}^{-1}\right)$ para a cultura do milho (CANTARELA; RAIJ; CAMARGO, 1996).

As dimensões das parcelas foram de $5 \mathrm{~m}$ de comprimento com 6 linhas espaçadas de $0,45 \mathrm{~m}$. Considerou-se como útil nas parcelas, as 2 linhas centrais com a cultura do feijão que coincidiram com as 2 linhas centrais da cultura antecessora (milho), cuja as parcelas apresentavam $5 \mathrm{~m}$ de comprimento com 4 linhas espaçadas de $0,90 \mathrm{~m}$.

Aárea experimental utilizada nos dois cultivos de feijão (2009 e 2010) foi a mesma e a cultura anterior nos dois cultivos foi o milho (safras 2008/2009 e 2009/2010), cujo os tratamentos aplicados foram os mesmos em ambos os cultivos. O experimento foi conduzido sob o sistema de semeadura direta já consolidado há oito anos, com uma estimativa média de aproximadamente $7 \mathrm{t} \mathrm{ha}^{-1}$ de palhada no solo.

A área foi dessecada utilizando os herbicidas, glifosato (1440 $\mathrm{g} \mathrm{ha}^{-1}$ do i.a.) e carfentrazona etílica (20 $\mathrm{g} \mathrm{ha}^{-1}$ do i.a.). Utilizou-se a cultivar IAC Carioca, semeando-se, em média, 15 sementes por metro de sulco. Asemeadura foi realizada mecanicamente, nos dias 18/05/2009 e 21/05/2010. Em seguida, a área foi irrigada por aspersão, por meio de pivô central com uma lâmina de água de aproximadamente 14 mm para promover a germinação das sementes. As plântulas emergiram 5 dias após a semeadura nos dois cultivos.

Aadubação de semeadura foi realizada com $30 \mathrm{~kg}$ ha $^{-1}$ de $\mathrm{N}$ (uréia) e $100 \mathrm{~kg} \mathrm{ha}^{-1}$ de $\mathrm{P}_{2} \mathrm{O}_{5}$ (superfosfato simples) igualmente para todos os tratamentos em 2009 e 2010, baseada na análise do solo e na recomendação de adubação para a cultura do feijão irrigado, para o Estado de São Paulo, conforme descrito por Ambrosano et al. (1997). A adubação potássica constituiu os tratamentos. Na adubação nitrogenada de cobertura foram aplicados $80 \mathrm{~kg} \mathrm{ha}^{-1}$ de N (uréia), distribuídos sobre a superfície do solo ao lado das entrelinhas a aproximadamente a $0,20 \mathrm{~m}$ das fileiras de plantas. Após a adubação nitrogenada, a área foi irrigada por aspersão, com uma lâmina de água de aproximadamente $14 \mathrm{~mm}$, para reduzir as perdas de $\mathrm{N}$ por volatilização da amônia.

O manejo de plantas daninhas foi efetuado com a aplicação do herbicida fomesafen $\left(250 \mathrm{~g} \mathrm{ha}^{-1}\right.$ do i.a.) e fenoxaprope-p-etílico ( $77 \mathrm{~g} \mathrm{ha}^{-1}$ do i.a.) em pós-emergência. $\mathrm{O}$ controle de insetos foi realizado com triazofos (175 $\mathrm{g} \mathrm{ha}^{-1}$ do i.a.), imidacloprido ( $80 \mathrm{~g} \mathrm{ha}^{-1}$ do i.a.) e deltametrina (32 $\mathrm{g} \mathrm{ha}^{-1}$ do i.a.). Para o controle de fungos e ácaros foi aplicado o mancozebe ( $800 \mathrm{~g} \mathrm{ha}^{-1}$ do i.a.). O fornecimento de água foi efetuado de três em três dias ou quando necessário por aspersão por meio de um sistema fixo de irrigação do tipo pivô central. $\mathrm{O}$ volume de rega da irrigação foi de $14 \mathrm{~mm}$.

O estande final da cultura do feijão foi de 266.667 e 311.111 plantas ha-1 em 2009 e 2010, respectivamente. A colheita foi realizada de forma manual aos 91 e 98 dias após emergêngia, para os cultivos realizados em 2009 e 2010, respectivamente, utilizando como parâmetro, quando $90 \%$ das vagens apresentavam $18 \%$ de umidade. O material colhido foi submetido à secagem a pleno sol e posteriormente trilhados. Em seguida, realizou-se a abanação manual para a limpeza do material.

As avaliações realizadas foram as seguintes: a) teor de potássio foliar, coletando-se a primeira folha amadurecida a partir da ponta do ramo, no início do florescimento das plantas, segundo a metodologia descrita por Malavolta, Vitti e Oliveira (1997); b) teor de clorofila foliar, determinado indiretamente na primeira folha madura do ápice de 3 plantas de feijão 
por parcela, quando as plantas estavam no estádio de florescimento da cultura através de leituras ICF, com auxílio de um clorofilômetro digital CFL 1030 Falker (Falker Automação Agrícola, Porto Alegre, Brasil); c) número de vagens por planta; d) número de grãos por vagem; e) número de grãos por planta; f) massa de 100 grãos, determinada em balança de precisão $0,01 \mathrm{~g}$; e g) produtividade de grãos, em kg ha $^{-1}$ corrigido para $13 \%$ (base úmida).

Os parâmetros avaliados foram submetidos à análise de variância, as médias das fontes de $\mathrm{K}$ foram comparadas pelo teste de Tukey a $5 \%$ de probabilidade e as doses de $\mathrm{K}_{2} \mathrm{O}$ usando ajustes de regressão polinomial.

\section{Resultados e Discussão}

Em 2009 e 2010, as fontes de K não diferiram significativamente para o teor de $\mathrm{K}$ foliar (Tabela 1). No primeiro ano, o valor apresentado foi inferior ao considerado adequado (20 a $25 \mathrm{~g} \mathrm{~kg}^{-1}$ de $\mathrm{K}$ na matéria seca) para o feijoeiro, em relação ao descrito por Malavolta, Vitti e Oliveira (1997), embora o teor de $\mathrm{K}$ encontrado no solo estivesse médio (2,2 $\mathrm{mmol}_{\mathrm{c}}$ $\left.\mathrm{dm}^{-3}\right)$. Esse fato, não se repetiu em 2010, pois os teores foliares de $\mathrm{K}$ de todos os tratamentos ficaram acima desta faixa considerada adequada para a cultura do feijão. Contudo, ressalta-se que essas fontes de $\mathrm{K}$ também não diferiram para o teor de $\mathrm{K}$ foliar do milho (cultutra antecessora) em ambas as safras, demonstrando assim, que o $\mathrm{KCl}$ revestido não se sobressaiu em relação ao $\mathrm{KCl}$ convencional. E que a produtividade média de grãos de milho foi de 8.113 e $8.122 \mathrm{~kg} \mathrm{ha}^{-1}$ para as safras $2008 / 09$ e 2009/10, respectivamente. Com relação às doses de $\mathrm{K}_{2} \mathrm{O}$, não houve efeito significativo para o teor de $\mathrm{K}$ foliar. Este não efeito da adubação potássica sobre o teor de K foliar também foi relatado por Silveira e Damasceno (1993) na cultura do feijão de inverno irrigado, e por Sguario Júnior et al. (2006), em duas safras de feijão de verão, em sistema de semeadura direta.

Os valores obtidos nas leituras de clorofila das folhas foram semelhantes em 2009 e 2010 (Tabela 1). Nos dois anos avaliados, o teor de clorofila (ICF) não apresentou diferença estatística para as fontes utilizadas de potássio. Contudo, o incremento das doses de $\mathrm{K}_{2} \mathrm{O}$ proporcionou aumento linear do teor de clorofila das folhas do feijoeiro, apenas em 2010. Esta elevação no teor de clorofila pode ser explicada, já que os cloroplastos contêm cerca de metade do $\mathrm{K}$ foliar, nutriente que promove maior difusividade do $\mathrm{CO}_{2}$ nas células do mesófilo, contribuindo assim para maior atividade fotossintética (PRADO, 2008).

As fontes de $\mathrm{K}$ não diferiram para os números de vagens por planta e de grãos por vagem, em ambos os cultivos (Tabela 1). Essa situação se repetiu com relação às doses de $\mathrm{K}_{2} \mathrm{O}$, não havendo ajuste para esses componentes avaliados. Silveira e Damasceno (1993) e Sguario Júnior et al. (2006) também não verificaram efeito de doses $\mathrm{K}_{2} \mathrm{O}$ para os números de vagens por planta e de grãos por vagem. Isto se justifica pelo fato de estas características apresentarem alta herdabilidade genética, sendo pouco influenciada pelo ambiente (ANDRADE et al., 1998). 
Tabela 1. Teores foliares de $\mathrm{K}$ e de clorofila (ICF), número de vagens por planta e número de grãos por vagem do feijoeiro de inverno irrigado, em função do residual de fontes de potássio e doses de $\mathrm{K}_{2} \mathrm{O}$. Selvíria - MS, 2009 e 2010.

\begin{tabular}{|c|c|c|c|c|c|c|c|c|}
\hline & \multicolumn{2}{|c|}{$\begin{array}{l}\text { Teor de } \mathrm{K} \text { foliar } \\
\left(\mathrm{g} \mathrm{kg}^{-1} \text { de MS }\right)\end{array}$} & \multicolumn{2}{|c|}{$\begin{array}{l}\text { Teor de clorofila } \\
\text { (ICF) }\end{array}$} & \multicolumn{2}{|c|}{$\begin{array}{l}\text { Número de vagens } \\
\text { por planta }\end{array}$} & \multicolumn{2}{|c|}{$\begin{array}{c}\text { Número de grãos } \\
\text { por vagem }\end{array}$} \\
\hline & 2009 & 2010 & 2009 & 2010 & 2009 & 2010 & 2009 & 2010 \\
\hline \multicolumn{9}{|l|}{ Fontes de $\mathrm{K}^{(1)}$} \\
\hline $\mathrm{KCl}$ & $16,75 \mathrm{a}$ & $28,18 \mathrm{a}$ & $41,34 \mathrm{a}$ & $41,64 \mathrm{a}$ & $12,00 \mathrm{a}$ & $7,80 \mathrm{a}$ & $5,12 \mathrm{a}$ & $4,58 \mathrm{a}$ \\
\hline $\mathrm{KCl}$ revestido & $17,56 \mathrm{a}$ & $28,31 \mathrm{a}$ & $40,77 \mathrm{a}$ & $41,86 \mathrm{a}$ & $12,56 \mathrm{a}$ & $8,12 \mathrm{a}$ & $5,33 \mathrm{a}$ & $4,59 \mathrm{a}$ \\
\hline D.M.S. $(\overline{5 \%})$ & $2, \overline{38}$ & $\overline{1}, \overline{1} 2$ & $\overline{1}, \overline{58}$ & $\overline{1}, \overline{4} 1$ & $\overline{1}, \overline{50}$ & $\overline{1}, \overline{3} 5$ & $0, \overline{3} \overline{8}$ & $\overline{0}, \overline{3} \overline{7}^{-}$ \\
\hline \multicolumn{9}{|c|}{$\begin{array}{c}\text { Doses de } \mathrm{K}_{2} \mathrm{O} \\
\left(\mathrm{kg} \mathrm{ha}^{-1}\right)^{(2)}\end{array}$} \\
\hline 0 & 19,13 & 28,50 & 40,25 & 40,29 & 11,75 & 7,15 & 4,98 & 4,60 \\
\hline 40 & 16,44 & 28,00 & 41,11 & 41,18 & 13,75 & 8,22 & 5,26 & 4,34 \\
\hline 80 & 17,13 & 28,25 & 41,12 & 42,06 & 12,13 & 8,85 & 5,23 & 4,65 \\
\hline 120 & 15,94 & 28,25 & 41,74 & 43,47 & 11,50 & 7,62 & 5,43 & 4,76 \\
\hline Média Geral & 17,16 & 28,25 & 41,05 & 41,75 & 12,28 & 7,96 & 5,22 & 4,59 \\
\hline C.V. $(\%)$ & 18,85 & 5,38 & 5,23 & 4,61 & 16,56 & 23,21 & 9,84 & 10,91 \\
\hline
\end{tabular}

(1) Médias seguidas de letra iguais, na coluna, não diferem entre si pelo teste de Tukey, a 5\% de probabilidade. (2) Equação de regressão para: teor de clorofila em $2010, \mathrm{Y}=40,1872+0,0260 \mathrm{X}\left(\mathrm{R}^{2}=0,98^{* *}\right)$.

Fonte: Elaboração dos autores.

Na Tabela 2, verifica-se que não houve diferença significativa entre $\mathrm{KCl}$ revestido e o $\mathrm{KCl}$ convencional para o número de grãos por planta, a massa de 100 grãos e a produtividade de grãos de feijão de inverno irrigado, tanto em 2009 quanto em 2010. Valderrama et al. (2011), avaliando a produtividade de grãos de milho nas mesmas condições edafoclimáticas de cerrado, constataram que o $\mathrm{KCl}$ revestido por polímeros teve a mesma eficiência que o $\mathrm{KCl}$ convencional, quando aplicados no sulco de semeadura da cultura. Entretanto, Guareschi et al. (2011) constataram que a aplicação a lanço de $\mathrm{KCl}$ revestido por polímeros, 15 dias antes da semeadura, proporcionou maior produção de matéria seca, número de vagens por planta e produtividade de grãos de soja em relação ao $\mathrm{KCl}$ convencional, em Rio Verde - GO. Segundo Shaviv (2001), o melhor desempenho das plantas a aplicação destes fertilizantes se deve ao fornecimento regular e contínuo de nutrientes às plantas e a redução de perdas de potássio por lixiviação.
De acordo com Vieira e Teixeira (2004), as respostas dos adubos peletizados dependem da ação microbiana; os quimicamente alterados irão converter parte dos nutrientes em formas insolúveis que serão disponibilizadas às plantas gradativamente; e por fim, os recobertos ou encapsulados consistem em compostos solúveis envoltos por uma resina permeável à água que irá regular o processo de fornecimento dos nutrientes. As taxas de liberação e dissolução de fertilizantes solúveis em água dependem dos materiais de revestimento (JAROSIEWICZ; TOMASZEWSKA, 2003). Ainda segundo estes autores, a liberação do nutriente irá depender da temperatura e umidade do solo. Além disso, a espessura e a natureza química da resina de recobrimento, a quantidade de microfissuras em sua superfície e o tamanho do grânulo do fertilizante determinam a taxa de liberação de nutrientes ao longo do tempo (GIRARDI; MOURÃO FILHO, 2003). Portanto, o tipo de polímero utilizado no $\mathrm{KCl}$ não foi eficiente na liberação gradativa de $\mathrm{K}$, provavelmente devido 
às condições edafoclimáticas da região, que apresenta elevadas temperaturas (Figura 1) e solo muito argiloso, que retêm umidade, podendo ter favorecido a rápida degradação deste polímero de revestimento. Assim, é provavel também que a maior solubilidade do $\mathrm{KCl}$ revestido tenha ocorrido já no cultivo do milho e não do feijoeiro. Visto que, uma maior precipitação e temperatura, condições citadas para maior solubilidade, foram maiores nos cultivos do milho. Sendo assim, ainda há necessidade de novas pesquisas para o desenvolvimento de novos polímeros para o revestimento do $\mathrm{KCl}$, que possam resistir as altas temperaturas que são comuns nesta região do cerrado de baixa altitude.

Com relação ao incremento das doses de $\mathrm{K}_{2} \mathrm{O}$, não houve efeito significativo para a massa de 100 grãos (Tabela 2). Sguario Júnior et al. (2006) também não constataram efeito do incremento de doses $\mathrm{K}_{2} \mathrm{O}$ na massa de 100 grãos do feijoeiro irrigado. Por sua vez, Silveira e Damasceno (1993) observaram que tal avaliação diminuiu significativamente com o aumento das doses deste nutriente e que, a maior massa de 100 grãos ocorreu sem a aplicação de potássio no solo.

Tabela 2. Número de grãos por planta, massa de 100 grãos e produtividade de grãos do feijão de inverno irrigado, em função do residual de fontes de potássio e doses de $\mathrm{K}_{2} \mathrm{O}$. Selvíria - MS, 2009 e 2010.

\begin{tabular}{|c|c|c|c|c|c|c|}
\hline & \multicolumn{2}{|c|}{ Número de grãos por planta } & \multicolumn{2}{|c|}{$\begin{array}{l}\text { Massa de } 100 \text { grãos } \\
(\mathrm{g})\end{array}$} & \multicolumn{2}{|c|}{$\begin{array}{c}\text { Produtividade de grãos } \\
\qquad\left(\mathrm{kg} \mathrm{ha}^{-1}\right)\end{array}$} \\
\hline & 2009 & 2010 & 2009 & 2010 & 2009 & 2010 \\
\hline \multicolumn{7}{|l|}{ Fontes de $\mathrm{K}^{(1)}$} \\
\hline $\mathrm{KCl}$ & $63,38 \mathrm{a}$ & 35,89 a & $27,64 \mathrm{a}$ & $26,23 \mathrm{a}$ & $3362 \mathrm{a}$ & $2938 \mathrm{a}$ \\
\hline $\mathrm{KCl}$ revestido & $64,81 \mathrm{a}$ & $38,20 \mathrm{a}$ & $27,81 \mathrm{a}$ & $25,72 \mathrm{a}$ & $3383 \mathrm{a}$ & $2977 \mathrm{a}$ \\
\hline D.M.S..$\overline{(5 \%})$ & $\overline{7,85}-$ & $-\overline{8,72}$ & 1,28 & $\overline{1}, 07$ & $\overline{171}$ & 200 \\
\hline \multicolumn{7}{|c|}{$\begin{array}{l}\text { Doses de } \mathrm{K}_{2} \mathrm{O} \\
\left(\mathrm{kg} \mathrm{ha}^{-1}\right)^{(2)}\end{array}$} \\
\hline 0 & 58,50 & 33,70 & 27,58 & 26,47 & 3300 & 2632 \\
\hline 40 & 72,25 & 36,08 & 28,28 & 25,93 & 3436 & 2997 \\
\hline 80 & 64,00 & 41,62 & 27,93 & 25,70 & 3334 & 3099 \\
\hline 120 & 61,25 & 36,78 & 27,12 & 25,77 & 3420 & 3101 \\
\hline Média Geral & 64,09 & 37,04 & 27,72 & 25,97 & 3373 & 2957 \\
\hline C.V. $(\%)$ & 16,65 & 32,00 & 6,27 & 5,65 & 6,92 & 9,22 \\
\hline
\end{tabular}

(1) Médias seguidas de letra iguais, na coluna, não diferem entre si pelo teste de Tukey, a 5\% de probabilidade. (2) Equações de regressão para: número de grãos por planta em $2009, \mathrm{Y}=59,8937+0,3051 \mathrm{X}-0,0025 \mathrm{X}^{2}\left(\mathrm{R}^{2}=0,63 *\right.$ e $\mathrm{PM}=61 \mathrm{~kg}$ ha-1 de $\left.\mathrm{K}_{2} \mathrm{O}\right)$ e produtividade de grãos em $2010, \mathrm{Y}=2731,4250+3,7700 \mathrm{X}\left(\mathrm{R}^{2}=0,76^{*}\right)$.

Fonte: Elaboração dos autores.

O número de grãos por planta foi influenciado positivamente pelas doses de potássio em 2009, ajustando-se à função quadrática com o valor máximo sendo alcançado com a estimativa de aplicação de $61 \mathrm{~kg} \mathrm{ha}^{-1}$ de $\mathrm{K}_{2} \mathrm{O}$, independentemente do $\mathrm{KCl}$ utilizado (Tabela 2). Já no segundo ano, não houve efeito significativo para tal avaliação. De acordo com Fageria e Santos (2008), esta importante característica da planta pode ser controlada geneticamente e também ser influenciada pelo manejo do solo e na planta.

A produtividade média de grãos de feijão de inverno irrigado foi mais elevada em 2009, em média, superior em $416 \mathrm{~kg} \mathrm{ha}^{-1}$ de grãos, quando comparado com produtividade da cultura no segundo ano, ou seja, em 2010, houve uma queda de $14 \%$ 
(Tabela 2). Estes resultados podem ser explicados pelo maior número de vagens e de grãos por planta observados em 2009 (Tabelas 1 e 2). Contudo, em 2009, o aumento das doses de potássio aplicados na cultura antecessora não afetou a produtividade de grãos de feijão. Este resultado pode ser devido ao teor médio de $\mathrm{K}\left(2,2 \mathrm{mmol}_{\mathrm{c}} \mathrm{dm}^{-3}\right)$ no solo, observado antes da instalação do experimento com milho safra $2008 / 2009$. Outro aspecto interessante, relatado por Giacomini et al. (2003), é que a maior parte do $\mathrm{K}$ dos resíduos culturais das plantas de cobertura é liberada logo após o manejo das espécies, pois apresenta pequena dependência dos processos microbianos.

Silveira e Damasceno (1993) também não verificaram aumento da produtividade de grãos de feijão comum irrigado, em sistema convencional, em função da aplicação de doses de potássio (0, 40, 80 e $120 \mathrm{~kg} \mathrm{ha}^{-1}$ de $\mathrm{K}_{2} \mathrm{O}$ ). Sguario Júnior et al. (2006), avaliando a aplicação de doses $(0,30,60,90$ e $120 \mathrm{~kg} \mathrm{ha}^{-1}$ de $\mathrm{K}_{2} \mathrm{O}$ ) e formas de aplicação (linha ou à lanço) de potássio, em duas safras de verão, também não constataram resposta de produtividade do feijão (cultivar IAC Carioca) em sistema de semeadura direta. Por sua vez, Braga et al. (1973), além de não encontrarem resposta do feijoeiro a adubação potássica, ainda observaram efeito depressivo das maiores doses de $\mathrm{K}_{2} \mathrm{O}$ (acima de 120 $\mathrm{kg} \mathrm{ha}^{-1}$ ) aplicadas no sulco de plantio da cultura.

No segundo ano de cultivo, as doses de potássio influenciaram positivamente a produtividade de grãos de feijão, ajustando-se à função linear crescente, independentemente da fonte de $\mathrm{K}$ aplicada na cultura antecessora (Tabela 2). Uma possível explicação para esta resposta positiva ao residual da adubação potássica, seria o aumento linear do teor de clorofila das folhas do feijoeiro em função do incremento das doses de $\mathrm{K}_{2} \mathrm{O}$ (Tabela 1), o qual deve ter proporcionado maior produção de fotoassimilados e consequentemente, maior crescimento e produtividade do feijoeiro.
Segundo Camargo (1970), plantas deficientes em K apresentam diminuição na fotossíntese e aumento da respiração, reduzindo o suprimento de carboidratos, o que provoca redução no crescimento das mesmas. Além disso, quando ocorre menor variação de temperatura no solo e maior disponibilidade de água (não neste estudo, no qual a cultura foi irrigada) há maior assimilação de potássio, principalmente em regiões de clima quente. Isto explica as diferenças de resposta ao $\mathrm{K}$, assim como diferenças de ano para ano.

Neste sentido, é interessante verificar o índice de produtividade da cultura e as condições de cultivo, para que se possa compreender a resposta da cultura a aplicação de potássio, assim como a possibilidade de se ter sucesso com o uso de fertilizantes revestidos.

\section{Conclusões}

$\mathrm{O} \mathrm{KCl}$ revestido por polímeros teve o mesmo efeito residual que $\mathrm{KCl}$ convencional, pois proporcionou resultados semelhantes para os teores foliares de $\mathrm{K}$ e de clorofila, os componentes de produção e a produtividade de grãos de feijão de inverno irrigado.

O incremento das doses de potássio na cultura anterior (milho) porporcionou efeito residual, pois influenciou positivamente o número de grãos por planta em 2009 e aumentou linearmente o teor de clorofila e a produtividade de grãos de feijão de inverno irrigado em 2010, independentemente da fonte de $\mathrm{K}$.

\section{Agradecimentos}

À Fundação de Amparo à Pesquisa do Estado de São Paulo pela concessão de bolsa de iniciação científica do primeiro autor e pelo apoio financeiro da pesquisa número 2009/00097-9. 


\section{Referências}

AMBROSANO, E. J.; TANAKA, R. T.; MASCARENHAS, H. A. A.; RAIJ, B. van; QUAGGIO, J. A.; CANTARELLA, H.; Leguminosas e oleaginosas. In: RAIJ, B. van; CANTARELLA, H.; QUAGGIO, J. A.; FURLANI, A. M. C. Recomendações de calagem e adubação para o Estado de São Paulo. Campinas: IAC, 1997. 285 p. (Boletim técnico, 100).

ANDRADE, M. J. B.; DINIZ, A. R.; CARVALHO, J. G. de; LIMA, S. F. Resposta da cultura do feijoeiro à aplicação foliar de molibdênio e às adubações nitrogenadas de plantio e cobertura. Ciência e Agrotecnologia, Lavras, v. 22, n. 2, p. 499-508, 1998.

AUOADA, F. A.; MOURA, M. R.; MENEZES, E. A.; NOGUEIRA, A. R. A.; MATTOSO, L. H. C. Síntese de hidrogéis e cinética de liberação de amônio e potássio. Revista Brasileira de Ciência do Solo, Viçosa, v. 32, n. 4, p. 1643-1649, 2008.

BARAMPAMA, Z.; SIMARD, R. E. Nutrient composition, protein quality and antinutritional factors of some varieties of dry beans. (Phaseolus vulgaris L.) grown in burundi. Food Chemistry, Barking, v. 47, n. 2, p. 159-67, 1993.

BLAYLOCK, A. O futuro dos fertilizantes nitrogenados de liberação controlada. Informações Agronômicas, Piracicaba, n. 120, p. 8-10, 2007.

BORKERT, C. M.; SFREDO, G. J.; FARIAS, J. R. B.; CASTRO, C. de; SPOLADORI, C. L.; TUDIDA, F. Efeito residual da adubação potássica sobre girassol e milho, em três diferentes Latossolos Roxos. Pesquisa Agropecuária Brasileira, Brasília, v. 32, n. 12, p. 1227 1234, 1997.

BRAGA, J. N.; DELFELIPO, B. V.; VIEIRA, C.; FONTES, L. A. N. Vinte ensaios de adubação N-P-K da cultura do feijão na zona da mata, Minas Gerais. Revista Ceres, Viçosa, v. 20, n. 111, p. 370-380, 1973.

CAMARGO, P. N. Princípios de nutrição foliar. São Paulo: Agronômica Ceres Ltda, 1970, 118 p.

CANTARELlA, H.; DUARTE, A. P. Manejo da fertilidade do solo para a cultura do milho. In: GALVÃO, J. C. C.; MIRANDA, G. V. Tecnologias de produção do milho. Viçosa, UFV. 2004. p. 139-182.

CANTARELLA, H.; van RAIJ, B.; CAMARGO, C. E. O. Cereais. In: van RAIJ, B.; CANTARELLA, H.; QUAGGIO, J. A. et al. (Ed.). Recomendações de adubação e calagem para o Estado de São Paulo. Campinas, Instituto Agronômico. 1996. p. 45-71. (Boletim técnico, 100)
CARVALHO, N. M.; NAKAGAWA, J. Sementes: ciência, tecnologia e produção. Jaboticabal: FUNEP, 2000. 429 p.

COMPANHIA NACIONAL DE ABASTECIMENTO CONAB. Safras-grãos: séries históricas relativas às safras 1976/77 a 2009/2010 de área plantada, produtividade e produção. 2011. Disponível em: <http://www. conab.gov.br/conteudos.php? $\mathrm{a}=1252 \& \mathrm{t}=1 \&$ Pagina objcmsconteudos $=2 \#$ A_objcmsconteudos $>$. Acesso em: 03 mar. 2011.

ECHER, F. R.; FOLONI, J. S. S.; CRESTE, J. E. Fontes de potássio na adubação de cobertura do algodoeiro I Produtividade, qualidade de fibras e análise econômica. Semina: Ciências Agrárias, Londrina, v. 30, p. 11351144, 2009. Suplemento 1.

FAGERIA, N. K.; SANTOS, A. B. Yield Physiology of dry bean. Journal of Plant Nutrition, Nova York, v. 31, n. 6, p. 983-1004, 2008.

GE, J. J.; WU, R.; SHI, X. H.; YU, H.; WANG, M.; LI, W. J. Biodegradable polyurethane materials from bark and starch. II. Coating materials for controlled-release fertilizer. Journal of Applied Polymer Science, Bognor Regis, v. 86, n. 12, p. 2948-2952, 2002.

GIACOMINI, S. J.; AITA, C.; HUBNER, A. P.; LUNKES, A.; GUIDINI, E.; AMARAL, E. B. Liberação de fósforo e potássio durante a decomposição de resíduos culturais em semeadura direta. Pesquisa Agropecuária Brasileira, Brasília, v. 38, n. 9, p. 1097-1104, 2003.

GIRARDI, E. A.; MOURÃO FILHO, F. A. A. Emprego de fertilizantes de liberação lenta na formação de pomares de citros. Revista Laranja, Cordeirópolis, v. 24, n. 2, p. 507-518, 2003.

GUARESCHI, R. F.; GAZOLLA, P. R.; PERIN, A.; SANTINI, J. M. K. Adubação antecipada na cultura da soja com superfosfato triplo e cloreto de potássio revestidos por polímeros. Ciência e Agrotecnologia, Lavras, v. 35, n. 4, p. 643-648, 2011.

JAMES, A. E.; SOJKA, R. E. Matrix based fertilizers reduce nitrogen and phosphorus leaching in three soils, Journal of Environmental Management, Cambridge, v. 87, n. 3, p. 364-372, 2008.

JAROSIEWICZ, A.; TOMASZEWSKA, M. Controlledrelease NPK fertilizer encapsulated by polymeric membranes. Journal of Agricultural and Food Chemistry, Washington DC, v. 51, n. 2, p. 413-417, 2003.

MALAVOLTA, E.; VITTI, G. C.; OLIVEIRA, S. A. Avaliação do estado nutricional das plantas: princípios e aplicações. 2. ed. Potafos: Piracicaba, 1997. 319 p. 
NI, B. L.; LIU, M. Z.; LÜ, S. Y. Multifunctional slow-release urea fertilizer from ethylcellulose and superabsorbent coated formulations. Chemical Engineering Journal, Nova York, v. 155, n. 3, p. $892-$ 898, 2009.

OLIVEIRA, I. P.; ARAÚJO, R. S.; DUTRA, L. G. Nutrição mineral e fixação biológica de nitrogênio. In: ARAÚJO, R. S. et al. (Coord.). Cultura do feijoeiro comum no Brasil. Piracicaba: Potafos, 1996. p. 169-221.

PRADO, R. de M. Nutrição de plantas. São Paulo: UNESP, 2008. 407 p.

RAIJ, B. van; ANDRADE, J. C.; CANTARELLA, H.; QUAGGIO, J. A. Análise química para avaliação da fertilidade de solos tropicais. Campinas: IAC, 2001. 285 p.

ROSOLEM, C. A.; MARUBAYASHI, O. M. Seja o doutor do seu feijoeiro. Informações Agronômicas, Piracicaba, n. 68, p. 1-16, 1994. Encarte Especial.

ROSSA, U. B. Fertilizante de liberação lenta no desenvolvimento de mudas de Paricá. Revista da Madeira, Brasília, n. 115, jul. 2008. Disponível em: $<$ http://www.remade.com.br/br/revistadamadeira materia.php? num $=1301 \&$ subject $=E \% 20$ mais \& title $=$ Fertilizante $\% 20 \mathrm{de} \% 20$ libera $\%$ E7\%E3o $\% 20$ lenta $\% 20$ no $\% 20$ desenvolvimento $\% 20$ de $\% 20$ mudas $\% 20$ de\%20Paric\%E1>. Acesso em: 15 maio 2011.

SANTOS, H. G. dos; JACOMINE, P. K. T.; ANJOS, L. H. C. dos; OLIVEIRA, V. A. de; OLIVEIRA, J. B. de; COELHO, M. R.; LUMBRERAS, J. F.; CUNHA, T. J. F. (Ed.). Sistema brasileiro de classificação de solos. 2. ed. Rio de Janeiro: Embrapa Solos, 2006. 306 p.

SGUARIO JÚNIOR, J. C.; DAROS, E.; PAULETTI, V.; RONZELLI JÚNIOR, P.; SOARES-KOEHLER, H.; OLIVEIRA, R. A. Doses e formas de aplicação de potássio na cultura do feijoeiro em sistema de semeadura direta na palha. Scientia Agraria, Curitiba, v. 7, n. 1-2, p .9-14, 2006.

SHAVIT, V.; REISS, M.; SHAVIV, A. Wetting mechanisms of gel-based controlled-release fertilizers. Journal of Controlled Release, Nottingham, v. 88, n. 1, p. 71-83, 2002.
SHAVIV, A. Advances in controlled-release fertilizers. Advances in Agronomy, Newark, v. 71, n. 5, p. 1-49, 2001.

SILVEIRA, P. M. da; DAMASCENO, M. A. Doses e parcelamento de $\mathrm{K}$ e de $\mathrm{N}$ na cultura do feijoeiro irrigado. Pesquisa Agropecuária Brasileira, Brasília, v. 28, n. 11, p. 1269-1276, 1993.

SOUSA, D. M. G.; REIN, T. A. Manejo da fertilidade do solo para culturas anuais: experiências no cerrado. Planaltina: EMBRAPA-CPAC, jun. 2009. 28 p. (EMBRAPA-CPAC. Informações Agronômicas, 126).

TEIXEIRA, I. R.; BORÉM, A.; ARAÚJO, G. A. A.; ANDRADE, M. J. B. Teores de nutrientes e qualidade fisiológica de sementes de feijão em resposta à adubação foliar com manganês e zinco. Bragantia, Campinas, v. 64, n. 1, p. 83-88, 2005.

VALDERRAMA, M.; BUZETTI, S.; BENETT, C. G. S.; ANDREOTTI, M.; TEIXEIRA FILHO, M. C. M. Fontes e doses de NPK em milho irrigado sob plantio direto. Pesquisa Agropecuária Tropical, Goiânia, v. 41, n. 2, p. 254-263, 2011

VIÉGAS, G. P.; FREIRE, E. S. Adubação do milho. XI efeito residual do fósforo. Bragantia, Campinas, v. 17, n. 21, p. 271-287, 1958.

VIEIRA, B. A. R. M.; TEIXEIRA, M. M. Adubação de liberação controlada chega como solução. Revista Campo \& Negócios, Uberlândia, v. 41, n. 3, p. 4-8, 2004.

WU, L.; LIU, M. Preparation and properties of chitosancoated NPK compound fertilizer with controlled-release and water-retention. Carbohydrate Polymers, New Jersey, v. 72, n. 2, p. 240-247, 2008.

XIE, L.; LIU, M.; NI, B.; ZHANG, X.; WANG, Y. Slowrelease nitrogen and boron fertilizer from a functional superabsorbent formulation based on wheat straw and attapulgite. Chemical Engineering Journal, Nova York, v. 167, n. 1, p. 342-348, 2011.

YAN, X.; JIN, J. J.; HE, P.; LIANG, M. Z. Recent advances in technology of increasing fertilizer use eficiency. Scientia Agricultura Sinica, Pequim, v. 41, n. 2, p. 450-459, 2008. 
